\title{
ELEMENTOS PARA A ANÁLISE DA CANÇÃO POPULAR*
}

\author{
L uiz Tatit \\ Universidade de São Paulo \\ tatit@usp.br
}

\section{A APREENSÃO EMPÍRICA DO OUVINTE}

Comum alguém dizer que ouviu um samba do Tom Jobim, um rock dos Titãs ou mais uma canção romântica do Roberto Carlos. Todas essas designações de gênero denotam a compreensão global de uma gramática. Significa que o ouvinte conseguiu integrar inúmeras unidades sonoras numa sequiência com outras do mesmo paradigma. Sambas, boleros, rocks, marchas... são ordenações rítmicas gerais que servem de ponto de partida para uma investigação mais detalhada da composição popular.

Uma outra forma de apreciação empírica da canção é a identificação dos estribilhos e dos mecanismos de reiteração. Trata-se também de um dispositivo de gramática melódica, fundamental para a retenção da memória e para as faculdades de previsão que esse tipo de linguagem temporal exige. A reiteração torna significativo o fluxo inexorável do tempo. Basta um ligeiro apuro musical do ouvido para se depreender reiterações.

Pouco mais refinada é a captação da tonalidade musical. No entanto, a sensação de que a melodia está mais tensa ou menos tensa é um efeito físico que o ouvinte, antes de compreender, já sente. Não é difícil demonstrar que as tensões harmônicas obedecem a uma hierarquia de

\footnotetext{
* Texto originalmente publicado na revista Cadernos de estudo: análise musical, n. 1, São Paulo, Atravez, 1989, e no livro Musicando a Semiótica: Ensaios/Luiz Tatit. São Paulo: Annablume, 1997.
} 
graus que regulamentam a trajetória da melodia e que toda vez que a tensão regride, 0 movimento corresponde a finalização.

E não é só a tonalidade que assegura a tensão. Toda inflexão da voz para a região aguda, acrescida de um prolongamento das durações, desperta tensão pelo próprio esforço fisiológico da emissão. Esta tensão física corresponde, quase sempre, a uma tensão emotiva e o ouvinte já está habituado a ouvir a voz do cantor em alta frequêencia relatando casos amorosos, onde há alguma perda ou separação que gera um grau de tensão compatível.

\section{A ATUAÇÃO DA FALA NA CANÇÃO}

A partir dessas percepções naturais da gramática rítmico-melódica, podemos constatar também a presença menos explícita, mas não menos importante, da linguagem oral em toda canção popular.

As mesmas consoantes que se transformam em ataques rítmicos e que, juntamente com os acentos vocálicos, contribuem para engendrar o gênero musical da canção, essas mesmas consoantes recortam a sonoridade da voz tornando-a inteligível e traduzindo-a nas oposições fonológicas e morfológicas que possibilitam, em outro nível, a depreensão de frases e de funções narrativas (sujeito/ objeto, destinador/ destinatário, persuasão/ interpretação, etc.). D aqui surge 0 conteúdo lingǘstico conhecido como o tema da canção.

As mesmas vogais que estabilizam a curva melódica numa sonoridade contínua, representando fisicamente as tensões emotivas, constituem a base para as inflexões entoativas da fala. 0 mesmo percurso melódico que registra a tensão passional acusa, simultaneamente, uma tensão própria do discurso oral: ascendência, suspensão e descendência (distensão) dos tonemas. ${ }^{1}$

A fala está presente, portanto, no mesmo campo sonoro em que atuam a gramática do ritmo fundando os gêneros e a gramática da freqüência fundando a tonalidade. A presença da fala é a introdução do timbre vocal como revelador de um estilo ou de um gesto personalista no interior da canção. Se o ouvinte chegar a depreender o gesto entoativo da fala no "fundo" da

\footnotetext{
${ }^{1}$ Os tonemas correspondem às terminações melódicas das frases enunciativas. Neles se concentra a maior parte do teor significativo das unidades entoativas. Cf. Navarro Tomas, Manual de entonacion española, Mexico, Malaga, 1966.
} 
melodia produzida pela voz, terá uma compreensão muito maior daquilo que sente quando ouve um canto.

\section{MELODIA E LETRA}

Tudo fica mais claro e mais completo ao se verificar a interdependência entre a melodia e a letra da canção. Se a reiteração e as tensões de altura servem para estruturar a progressão melódica, esses mesmos recursos podem ser transferidos ao conteúdo, de modo a construir uma significação compatível.

A qualificação de um personagem (a baiana, a mulata, o folião, o jovem ou o próprio narrador) ou de um objeto (o samba, a dança, o país, etc.) é uma das principais formas de manifestação da reiteração na letra. A exaltação, a enumeração das ações de alguém (0 esaurinho ou Pedro Pedreiro, por ex. ) ou a própria construção de um tema homogêneo (a rotina em Cotidiano ou V oô não entende nada ou ainda a natureza em Á guas de março ou Refazenda, por ex.), funcionam muito bem como espelhamento das reincidências melódicas. Este tipo de compatibilidade simples já permite a identificação de inúmeras canções quase didaticamente construídas: Falsa baiana, 0 que é que a baiana tem, Palon, G arota de Ipanema, Beleza pura, etc.. Reiteração da melodia e reiteração da letra correspondem à tematização.

A configuração de um estado passional de solidão, esperança, frustração, ciúme, decepção, indiferença, etc., ou seja, de um estado interior, afetivo, compatibiliza-se com as tensões decorrentes da ampliação de frequêencia e duração. Como se à tensão psíquica correspondesse uma tensão acústica e fisiológica de sustentação de uma vogal pelo intérprete. 0 prolongamento das durações torna a canção necessariamente mais lenta e adequada à introspecção. Afinal, a valorização das vogais neutraliza parcialmente os estímulos somáticos produzidos pelos ataques das consoantes. 0 corpo pode permanecer em repouso, apenas com um leve compasso garantindo a continuidade musical. Todas as canções românticas possuem essas características próprias do processo de passionalização.

E, por fim, a presença da fala também repercute na letra da canção. Todos os recursos utilizados para presentificar a relação eu/ tu (enunciador/ enunciatário) num aqui/ agora contribuem para a construção do gesto oral do cancionista. Ao ouvirmos vocativos, imperativos, demonstrativos, etc., temos a impressão mais acentuada de que a melodia é também uma entoação lingüística e que a canção relata algo cujas circunstâncias são revividas a cada execução. 
O cancioneiro popular traz diversos exemplos, como Conversa de botequim, A corda amor, D a maior importância,V ocê não soube me amar, Sinal fechado, etc., todos inscritos no processo de figurativizacãa enunciativa.

A presença simultânea da tematização, da passionalização e da figurativização no mesmo campo sonoro e o revezamento das dominâncias de um processo sobre o outro constituem 0 projeto geral de dicãão do cancionista. ${ }^{2} \mathrm{~A}$ composição, em si, já propõe uma dicção que pode ser transformada ou aprimorada pela interpretação do cantor, pelo arranjo e pela gravação. Para captarmos as dominâncias, precisamos estar bem familiarizados com as características específicas de cada um dos processos.

\section{AMOSTRA DE ANÁLISE}

A análise do trecho de uma conhecida canção de Gilberto Gil, utilizado como abertura da novela 0 salvador da pátria, em 1989, talvez possa dar um exemplo de conduta descritiva visando especialmente a relação da letra com a melodia. ${ }^{3}$

\section{Primeira parte:}

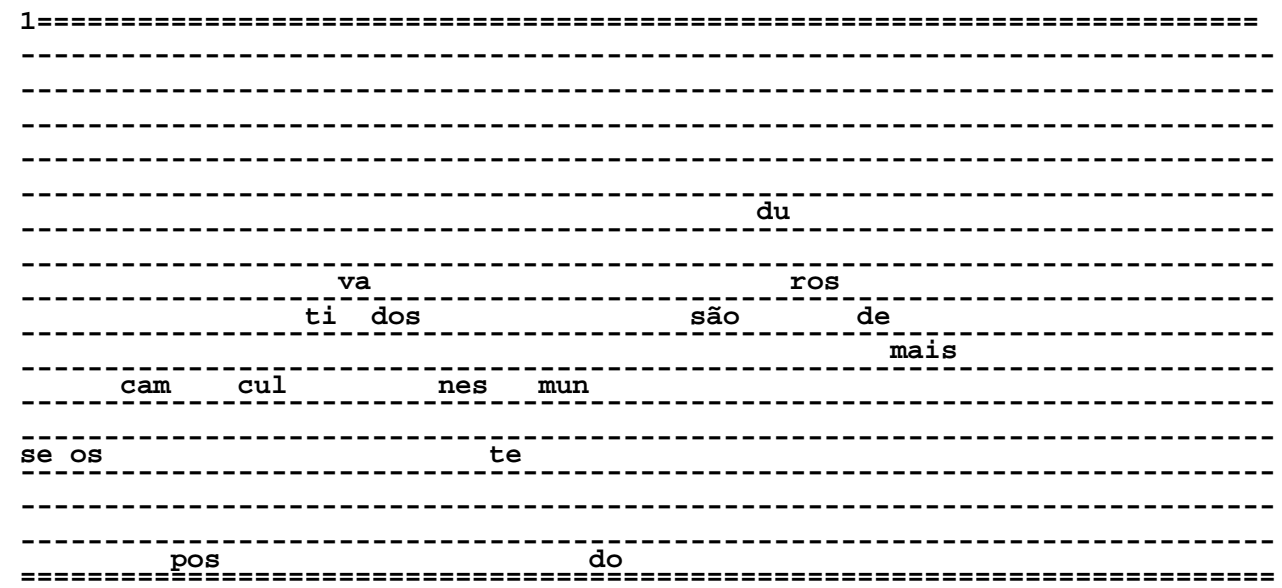

${ }^{2}$ Cf. L. Tatit, O cancionista, op. cit., p. 9-27.

${ }^{3}$ Vimos propondo um mapeamento dos contornos melódicos a partir da própria letra da canção, como um campo de referência aos nossos comentários, esperando que o leitor-ouvinte elabore mentalmente o exemplo. A acentuação natural das palavras sugere, por si só, um tratamento rítmico que se define num contexto de familiaridade com a música. Os espaços entre as linhas determinam as gradações em semitons, enquanto as linhas mais espessas delimitam a região de tessitura ocupada pela canção. 


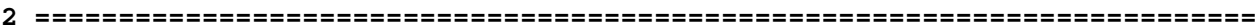

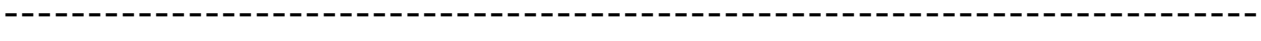

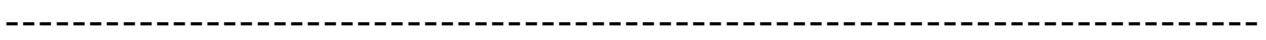

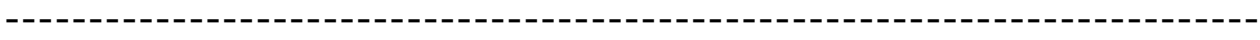

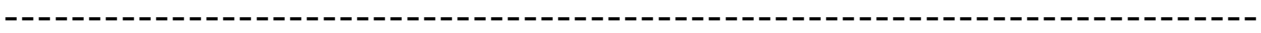

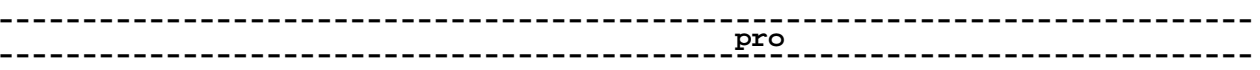

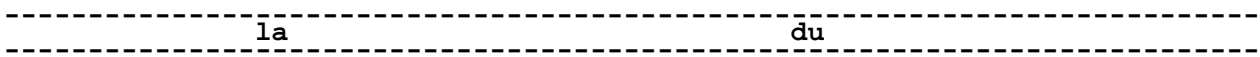

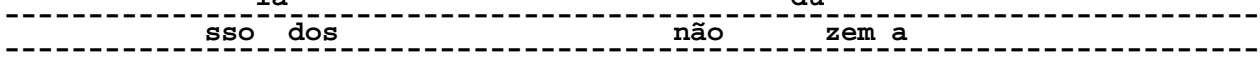

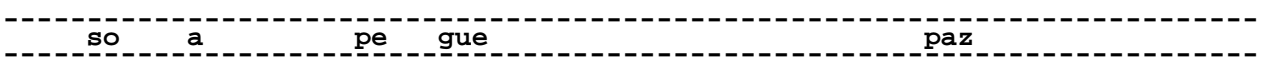

\begin{tabular}{|c|c|}
\hline$\overline{\mathrm{E}} \mathrm{OS}$ & la \\
\hline
\end{tabular}

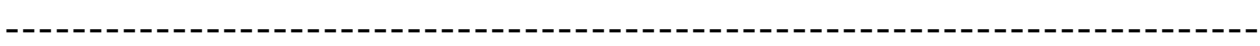

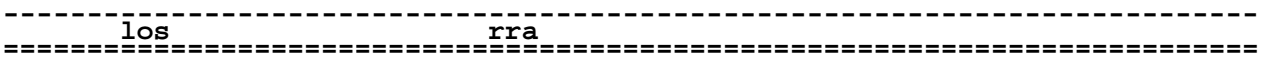

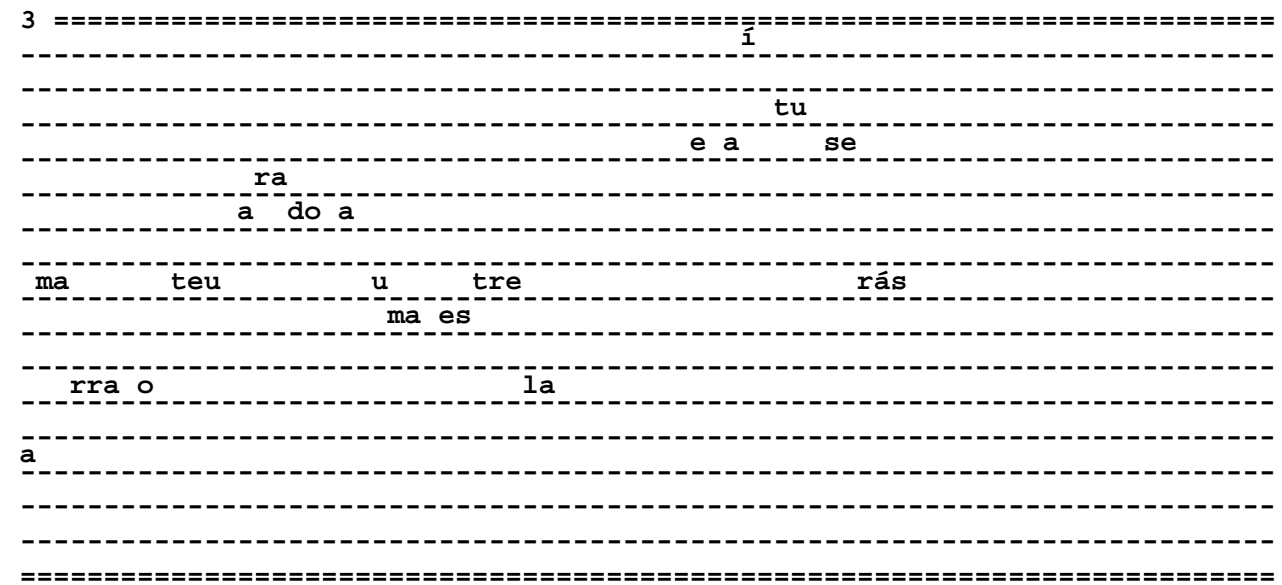




\section{Segunda parte:}

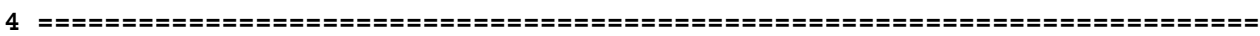

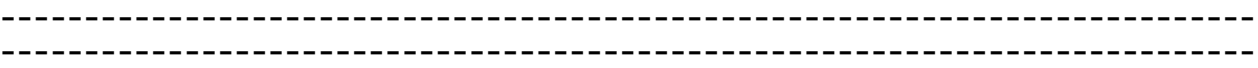

oㅡ므므믐ór

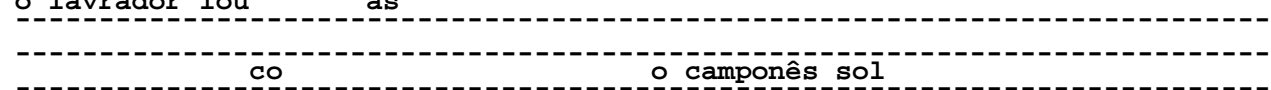

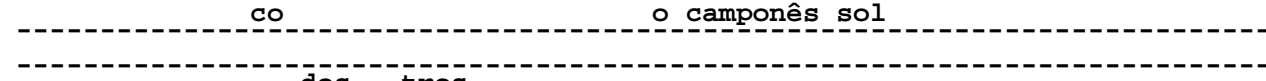

-

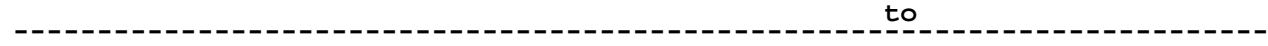

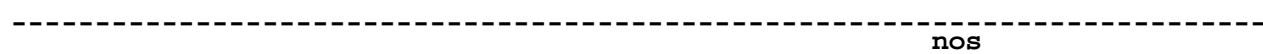

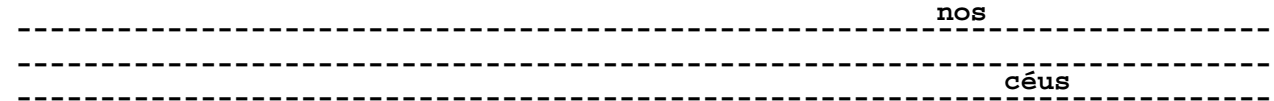

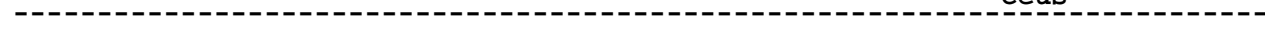

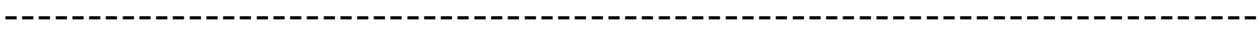

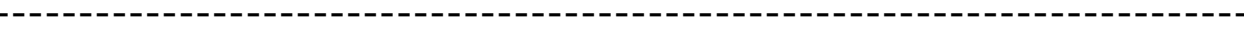

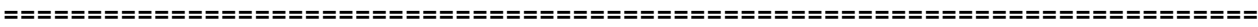

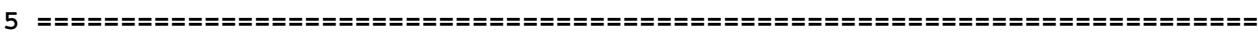

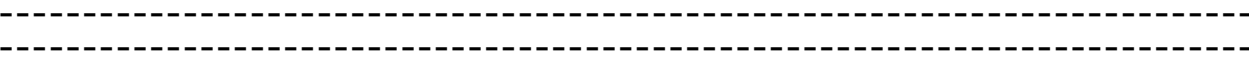

é quantómais

ếquanto mais lon

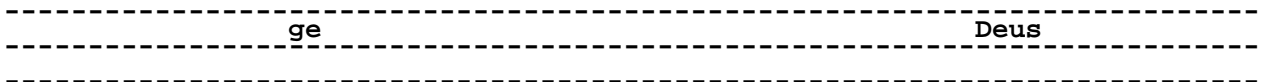

-----------------_da

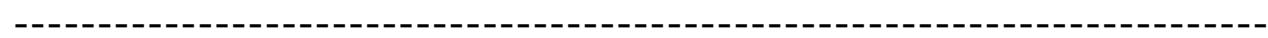

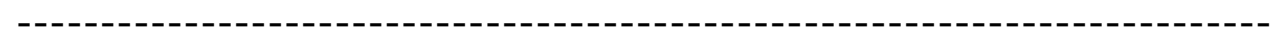

--- - - - - - - - - - - - - - - - - - - - - - - - - - - - - - - - - - - - - - - - - - - - - - - - - - - - - - - - - - -

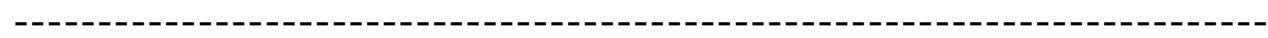

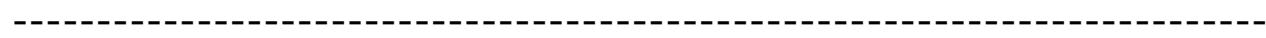

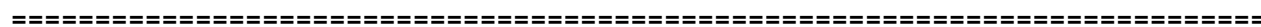


Concebida por compositor de larga experiência no mercado fonográfico, A marra 0 teu arado a uma estrela ${ }^{4}$ apresenta um perfil melódico extremamente econômico, na medida justa para a retenção da memória, contendo apenas os elementos essenciais que caracterizam, com inteireza, um sentido melódico. Grosso modo, somente dois desenhos entoativos compõem a seqüência completa desta canção, separando os três primeiros segmentos (primeira parte) dos dois últimos (segunda parte).

\section{Primeira parte}

Apesar de os três segmentos iniciais manterem o perfil, somente os dois primeiros são idênticos. 0 terceiro já acusa uma transformação no campo de tessitura e no tratamento instrumental de fundo.

A identidade de perfil pode ter um valor temático quando essa reiteração melódica ecoa a recorrência de gestos somáticos ou de elementos sensitivos relatados na letra ou, ainda, quando a regularidade firmada em suas acentuações entra em sintonia fisiológica com o ouvinte. Mas pode também ter um valor figurativo quando a reincidência dos motivos serve para forjar uma enumeração entoativa à maneira da linguagem coloquial. Uma apreciação preliminar da melodia já revela tendências virtuais da curva antes mesmo da influência decisiva da letra.

(1) A desigualdade dos fragmentos que integram cada segmento melódico tolhe a fluência rítmica da seqüência, diminuindo a importância de uma eventual adesão corporal do ouvinte nesta fase.

\footnotetext{
${ }^{4}$ Grav. n. 63558912 In: O salvador da pátria, Som Livre, 1989. Escolhemos, desta canção, o trecho consagrado pela citada novela da Rede Globo de TV. A música completa compreende duas versões de texto referentes à mesma melodia. Nossa escolha se deve (1) à provável familiaridade do leitor com este trecho, (2) à similaridade dos procedimentos de composição nas duas versões e, por fim, (3) à intenção de não estender demasiadamente os limites da análise. Transcrevo, aqui, a versão não considerada: Se os frutos produzidos pela terra / Ainda não são tão / Doces e polpudos quanto às peras / Da tua ilusão / Amarra o teu arado a uma estrela / E os tempos darão / Safras e safras de sonhos / Quilos e quilos de amor / Noutros planetas risonhos / Outras espécies de dor.
} 


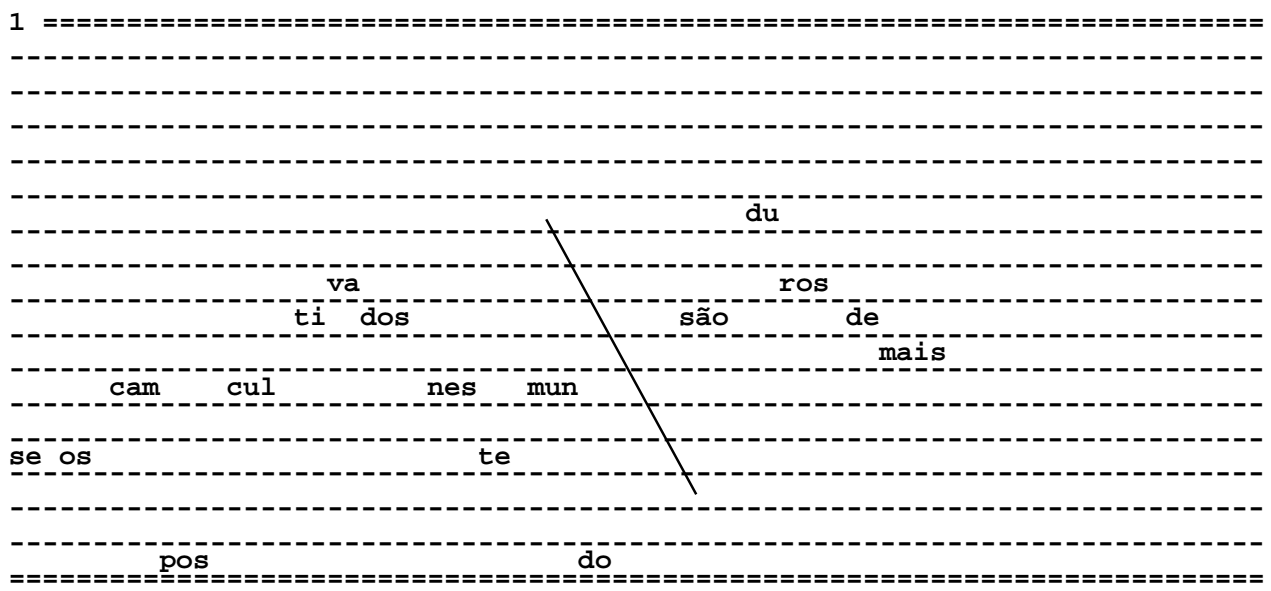

(2) Embora os acentos obedeçam à marcação periódica, não há ainda aceleração suficiente para que os ataques consonantais se sobreponham às durações vocálicas. Ao contrário, são essas que, nos tempos fortes, vão sendo captadas auditivamente como pontos de referência para a posterior elevação da freqüência, durante o terceiro segmento.
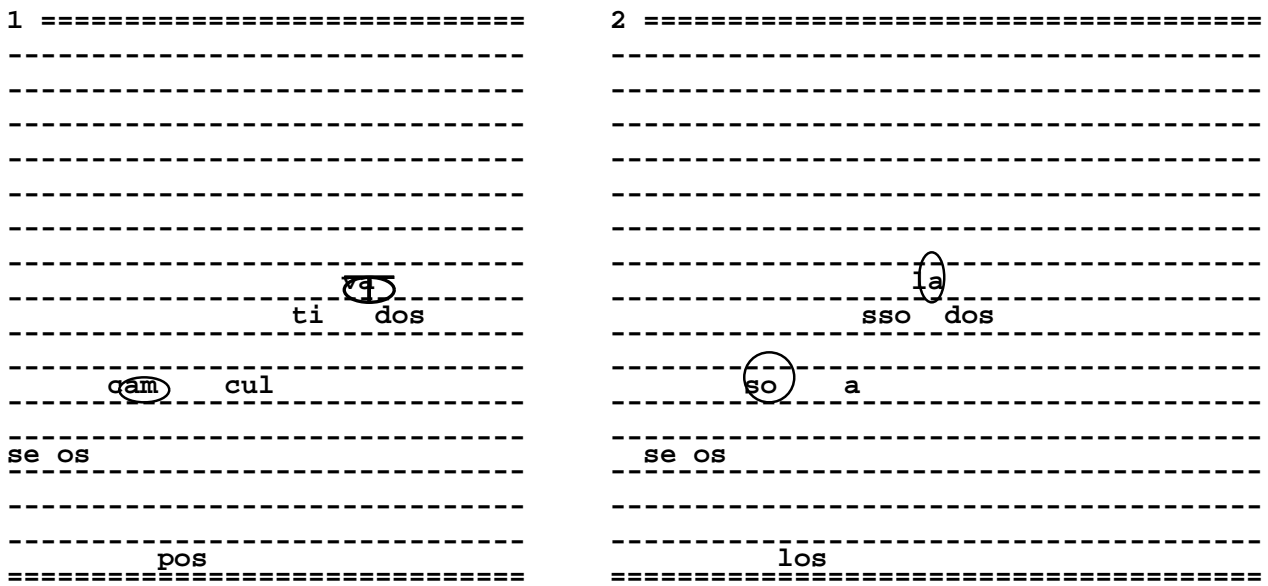


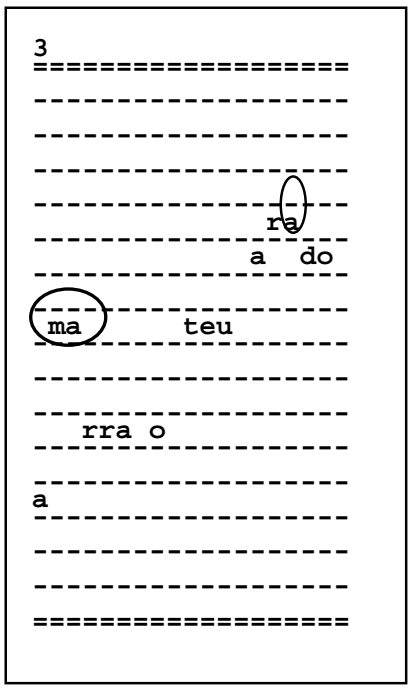

(3) 0 realce das vogais, mesmo fora de um prolongamento expressivo de sua duração, atenua a função dos ataques (dos recortes) das consoantes, evitando uma excessiva dinamização do continuum temporal. Emprestando, aqui, uma noção de Eero Tarasti, ${ }^{5}$ podemos dizer que a desativação do tempo musical -basicamente, pela moderação dos recortes e pela desaceleração do andamentoreflete a atuação da modalidade do / ser/ sobre o devir melódico, enquanto o processo inverso de ativação do tempo musical -dentro de uma tematização stricto sensu- reflete a atuação da modalidade do / fazer.${ }^{6} \mathrm{~A}$ modalização do / ser/, que subjaz à melodia e à letra ao mesmo tempo, camufla os estímulos corporais próprios da ação, em proveito de um estado psíquico propenso à paixão.

Ao longo desses três segmentos iniciais, se observássemos exclusivamente 0 perfil melódico, verificaríamos a influência das duas modalidades, com progressiva dominância do / ser/ sobre o / fazer/ . De fato, o andamento pausado da melodia, valorizando as durações e os acentos das freqüências mais elevadas sintomatiza a modalização do / ser/ e cria uma atmosfera propícia à passionalização. Q uando, neste contexto, o perfil do terceiro segmento desloca-se para o agudo, o quadro passional parece ainda mais definido no plano emotivo, pois cria-se um foco de tensão (alta freqüência) fartamente sugestivo para uma elaboração da letra da mesma orientação. 0 pico do primeiro fragmento eleva-se três semitons, enquanto que o do segundo eleva-se mais quatro, demarcando o fronteira superior do campo de tessitura.

\footnotetext{
5 "Le rôle du temps dans le discours musical", in: M. Arrivé et J-Cl. Coquet (eds.), Sémiotique en jeu, op. cit., p. 127.

${ }^{6}$ Tarasti transfere as modalidades do /ser/ e do /fazer/ de seu habitual contexto narrativo para o domínio da música erudita. Cogitamos que essa derivação ganharia um peso ainda maior no terreno da canção popular, onde melodia e letra são regidas pelos mesmos princípios.
} 


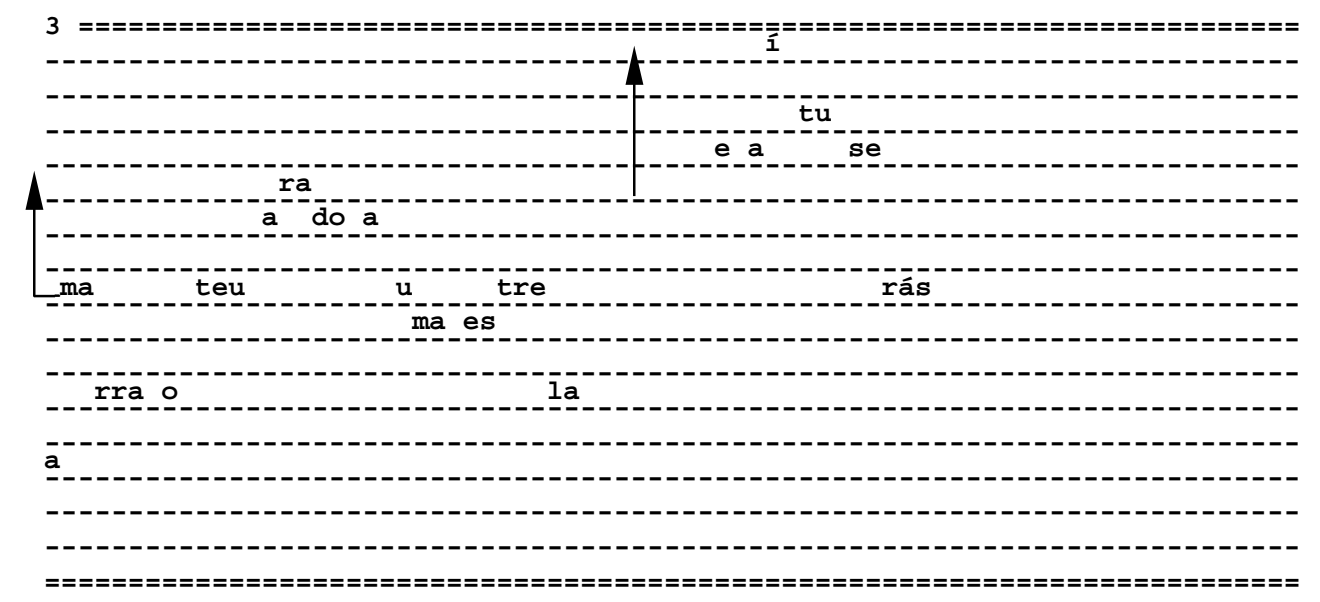

Entretanto, a base instrumental que acompanha a seqüência desde 0 início desfaz essa tendência ao atingir o limiar do terceiro segmento. A dinâmica incorporada a partir deste momento imprime na linha melódica uma nova fisionomia musical. Os acentos, a pulsação e a periodicidade passam para o primeiro plano evidenciando um / fazer/ relativamente ofuscado nos segmentos anteriores. Ao invés de referendar o projeto de passionalização inscrito na elevação melódica, esse novo tratamento se impõe como prenúncio de uma tematização ainda mal configurada. Esta condição, aliás, é própria da continuidade melódica cujos fragmentos estão sempre duplamente comprometidos, com o que passou e com o que está por vir. Só o recorte promovido pela letra, como veremos à frente, pode definir de vez a ação do devir melódico.

O discreto compromisso com a tematização nos dois primeiros segmentos e o estreitamento deste laço a partir do terceiro permitem extrair duas conclusões a respeito da melodia: 
A identidade de perfil, nos dois segmentos iniciais, evidencia um valor figurativo (em nossa fala cotidiana, repetimos o motivo entoativo ao enumerarmos fatos de mesma natureza). Nessa perspectiva, cabe observar ainda o caráter descendente dos tonemas de todos os fragmentos, incluindo os do terceiro segmento, instaurando um contexto geral de asseveração que vai influir diretamente na formação de mensagem da letra.
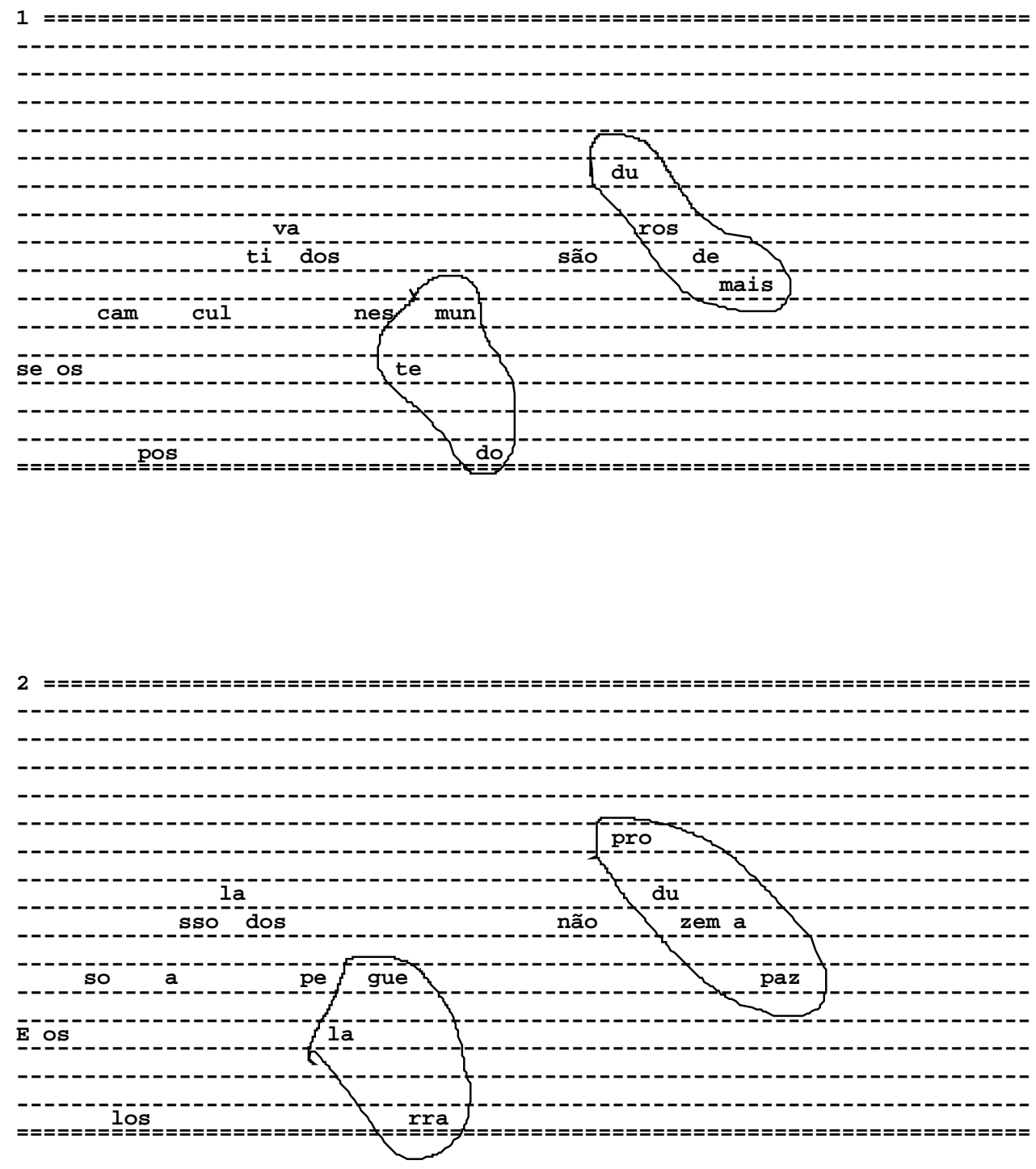


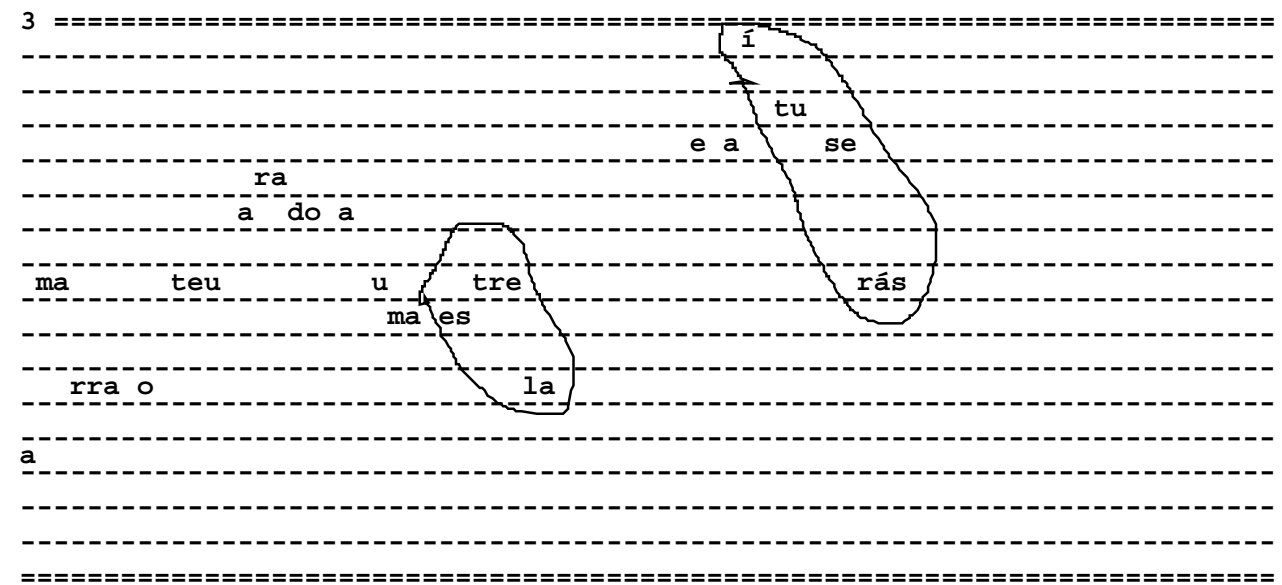

Tal asseveração é ainda reforçada pela aceleração terminativa dos fragmentos menores, localizados à direita do diagrama, que funcionam como arremates enunciativos das respectivas frases anteriores.

0 terceiro segmento desempenha uma função transformadora dentro do contexto melódico global da canção. De um lado, o acréscimo de tensão no nível da freqüência sugere um processo de passionalização. De outro, a dinamização do acompanhamento de base, na abertura deste segmento, revitaliza o valor temático que permanecera diluído nas seqüências anteriores. Afinal, a reiteração do perfil e a regularidade rítmica já vêm se conformando desde 0 início, faltando apenas serem devidamente sublinhadas.

A compatibilização da melodia com a letra é notória:

"Se os campos cultivados neste mundo

São duros demais

E os solos assolados pela guerra

Não produzem a paz

Amarre o teu arado a uma estrela

E aí tu serás

O lavrador louco dos astros

O camponês solto nos céus

E quanto mais longe da terra

Tanto mais longe de Deus" 
Do ponto de vista figurativo, a reiteração da curva incide sobre a enumeração de elementos de mesma natureza, os "campos" e os "solos", enquanto os tonemas descendentes constatam as condições insatisfatórias em que eles se encontram: "são duros demais" e "não produzem a paz". Tais valores figurativos, entretanto, só serão devidamente dimensionados na abertura do terceiro segmento, com a inclusão do imperativo: "amarra". Este modo verbal realiza, com plenitude, a vocação entoativa da melodia de canção, pois que sua aplicação instaura, simultaneamente, uma relação de comunicação direta (eu/tu) fundada num aqui/agora incontestável. 0 imperativo presentifica o tempo e o espaço enunciativo, exacerbando os efeitos entoativos (no sentido de que o cantor fala ao mesmo tempo que canta) inerentes à melodia vocal. D esempenha, quase sempre, a função de núcleo da figurativização.

Nessa concepção, o verso "amarra o teu arado a uma estrela" ocupa o centro nevrálgico da mensagem figurativa, onde 0 enunciador emite sua sugestão metafórica como alternativa para se escapar às coerções deste mundo.

Do ponto de vista passional, a condição deflagradora é o sentimento de falta determinado pelos traços de esterilidade (improdutividade) que virtualizam uma possível busca de fecundidade. A disjunção com os valores positivos, aqueles que ainda não germinam em nosso planeta, é um dos efeitos da modalização do / ser/ sobre a letra. Assim como a melodia progride de maneira pausada, a letra vai revelando as carências que estão na base da expectativa subjetiva. Tudo conflui para a paixão que deveria se consolidar na elevação de freqüência (tensão passional) do terceiro segmento. Entretanto, como já observamos, neste momento surge a intervenção determinante da base instrumental que se alia diretamente à frase da letra, extraindo da melodia, não o sentido passional prefigurado, mas os valores da tematização discretamente ensaiados nos segmentos iniciais.

Do ponto de vista temático, portanto, a leitura deste terceiro segmento complementa e expande 0 viés figurativo, deixando a passionalização em segundo plano.

"Amarra o teu arado a uma estrela" é uma proposta de ação ainda que "arado" só se relacione com "estrela" num plano metafórico. Trata-se de uma solução que interrompe 0 quadro passional que vinha se desenhando. Ao invés de ampliar a tensão psíquica, na mesma proporção do aumento de freqüência, o enunciador reverte a tendência propondo uma transformação típica do / fazer/ . Com a ação, cessa a hegemonia da paixão: 0 sentimento de falta se converte em projeto de busca (ou, ainda, de liquidação da falta). D aí então a compatibilidade, 
aliás muito freqüente, da letra com 0 arranjo instrumental. A ação descritiva no primeiro é solidariamente incentivada no segundo.

Disso decorre um grande fator de unidade desta canção. Este terceiro segmento está vinculado à primeira parte (ou, mais precisamente, aos dois primeiros segmentos) pela continuidade do perfil melódico, mas já antevê as diretrizes da segunda parte pela letra e pelo arranjo instrumental. Tal intersecção contribui para uma passagem gradual sem rupturas.

\section{Segunda Parte}

A alteração do perfil melódico, a partir do quarto segmento, traz uma nova concepção seqüencial em relação às unidades da primeira parte:

(1) Os fragmentos são dinamizados com um recorte mais minucioso do tempo rítmico de cada compasso, acelerando o andamento.

(2) As quatro subsequiências (ou fragmentos) dos segmentos 4 e 5 recebem um tratamento bem mais homogêneo que o da primeira parte. Equivalentes do ponto de vista rítmico (exceto na região dos tonemas), o sentido reiterativo da melodia torna-se mais claro e determinante na audição.

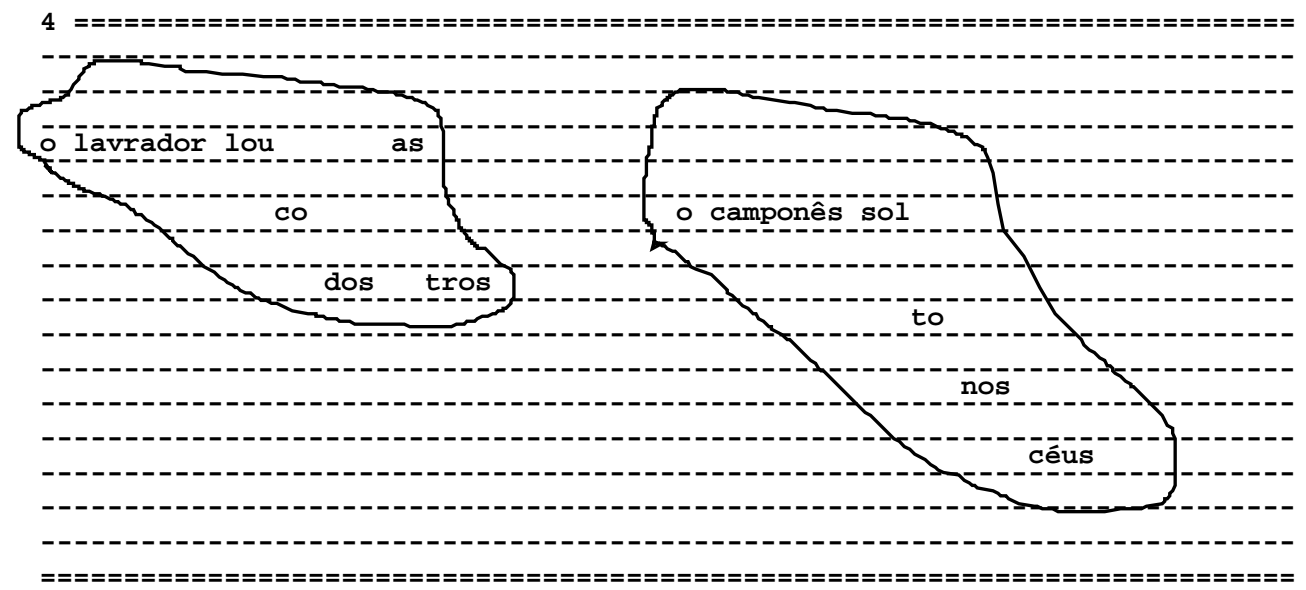




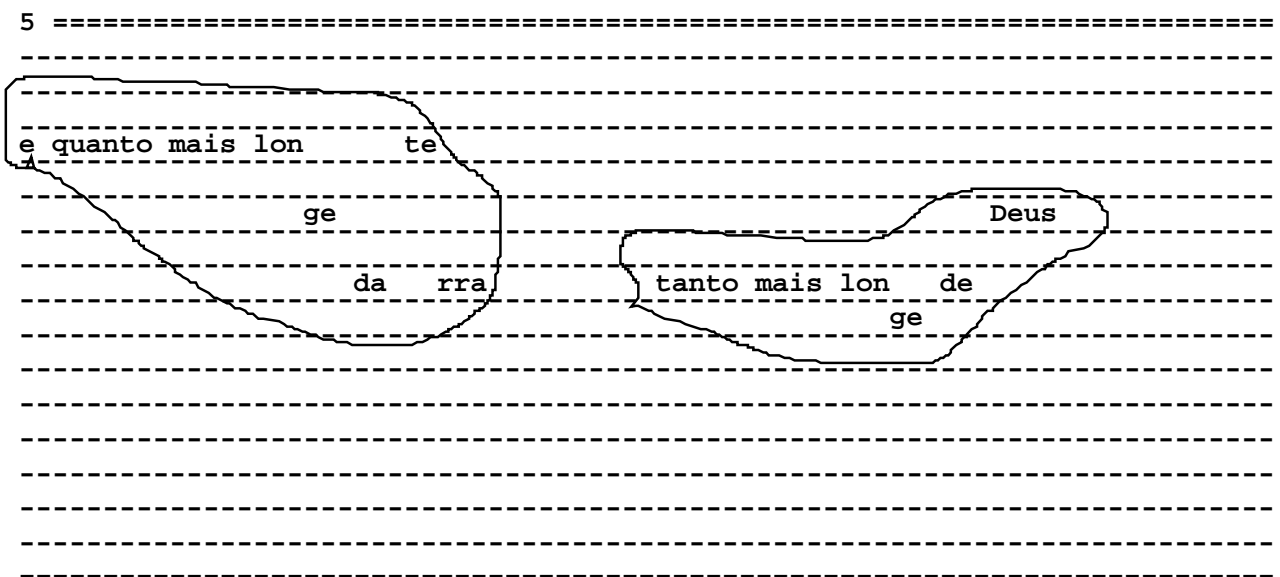

(3) Esses traços suprimem o ritmo pausado da parte inicial e ampliam consideravelmente a vocação temática da linha melódica. Não se pode deixar de reconhecer, contudo, uma dimensão figurativa que permanece nas oposições dos tonemas,

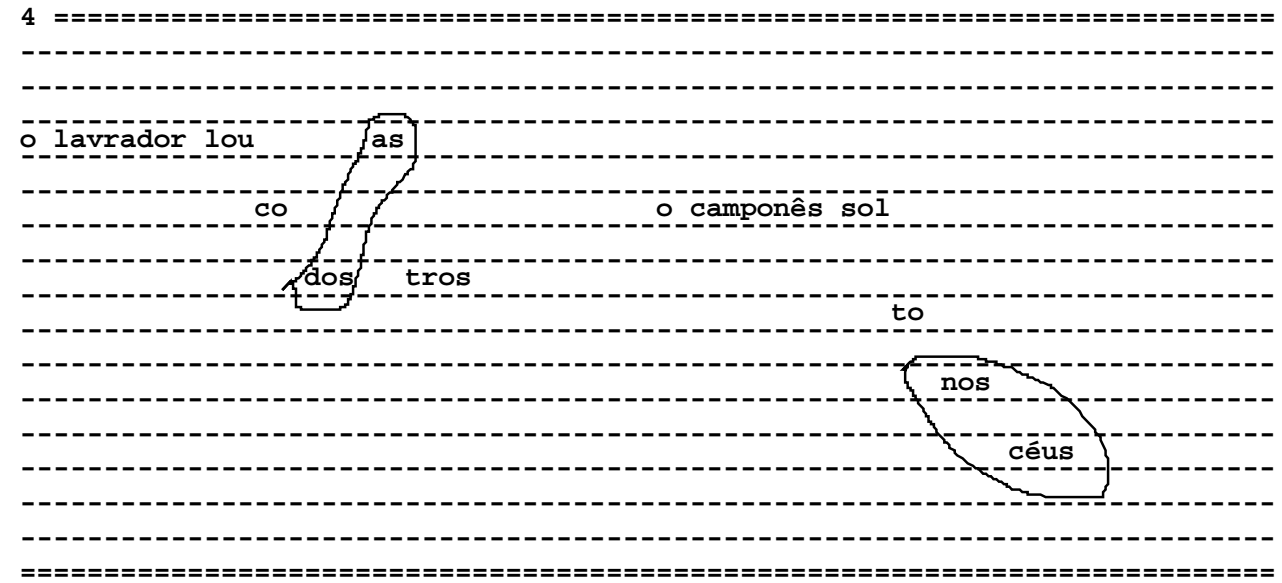


e mesmo as duas marcas passionais expressas com lirismo nas durações agudas dos primeiros fragmentos:
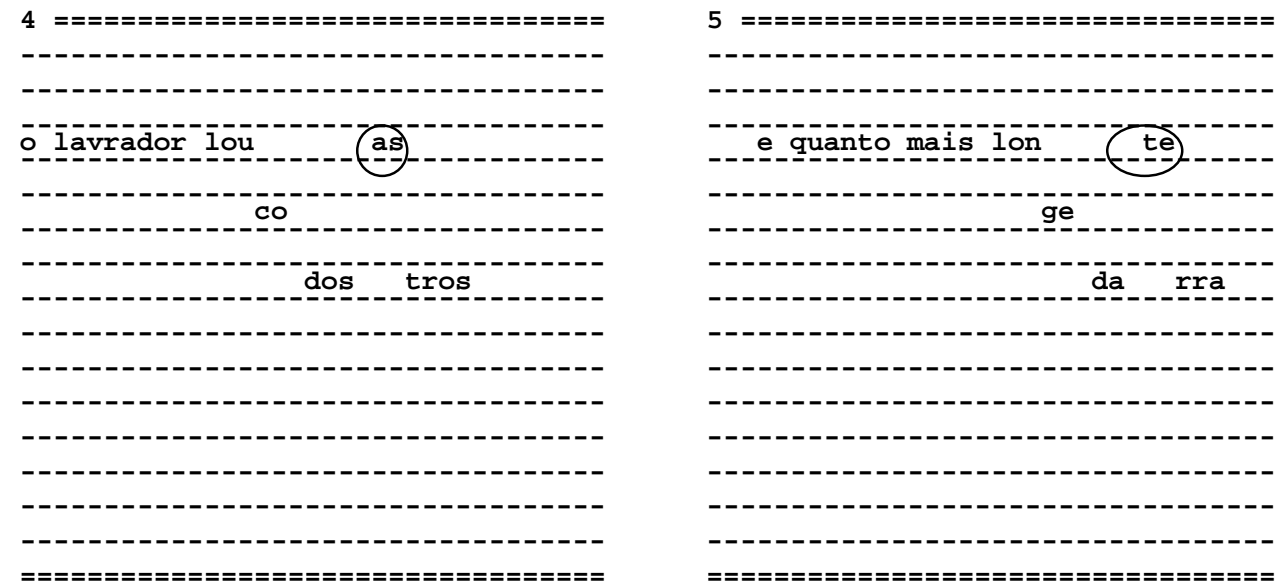

A permanência mais prolongada da voz nessas duas sílabas preserva uma espécie de seqüela passional, provocada pela idéia de afastamento (metafórico) da terra. Apesar de 0 contexto geral apresentar essa busca da fecundidade interplanetária como uma solução, há um fundo, digamos, dialético, que identifica essa nova aquisição com um outro tipo de perda ("outras espécies de dor" na versão da letra não descrita aqui). E tal equação vem formulada nos versos: "E quanto mais longe da terra / tanto mais longe de Deus". Uma vez mais, a tensão de freqüência representa a tensão de afastamento de um objeto de valor.

No plano figurativo, esta composição adota decididamente a asseveração: nos dois primeiros segmentos, por se tratar das constatações (ou condições) iniciais que irão deflagrar as situações posteriores; no terceiro segmento, por ser a voz imperativa que pratica a recomendação de uma proposta de ação; nos últimos, finalmente, por refletir o resultado e a avaliação feita pelo próprio enunciador. Aqui, o comportamento das inflexões segue o padrão lógico de entoação das frases enunciativas, em que a primeira seqüência se eleva para valorizar o aspecto conclusivo da descendência final (cf. no penúltimo diagrama acima, a melodia do segmento 4.).

Se, no quinto segmento, o tonema final aparece invertido, é mais por acréscimo que por mudança de sentido. A asseveração persiste na base harmônica, reforçada, inclusive, pela sétima dominante que prepara a resolução do último acorde. 0 emprego de uma forma tonêmica 
ascendente para atingir a tonalidade tem, aqui, um valor temático no sentido de "chamar" musicalmente os improvisos vocais onomatopaicos, pronunciados em "uou, uou...".

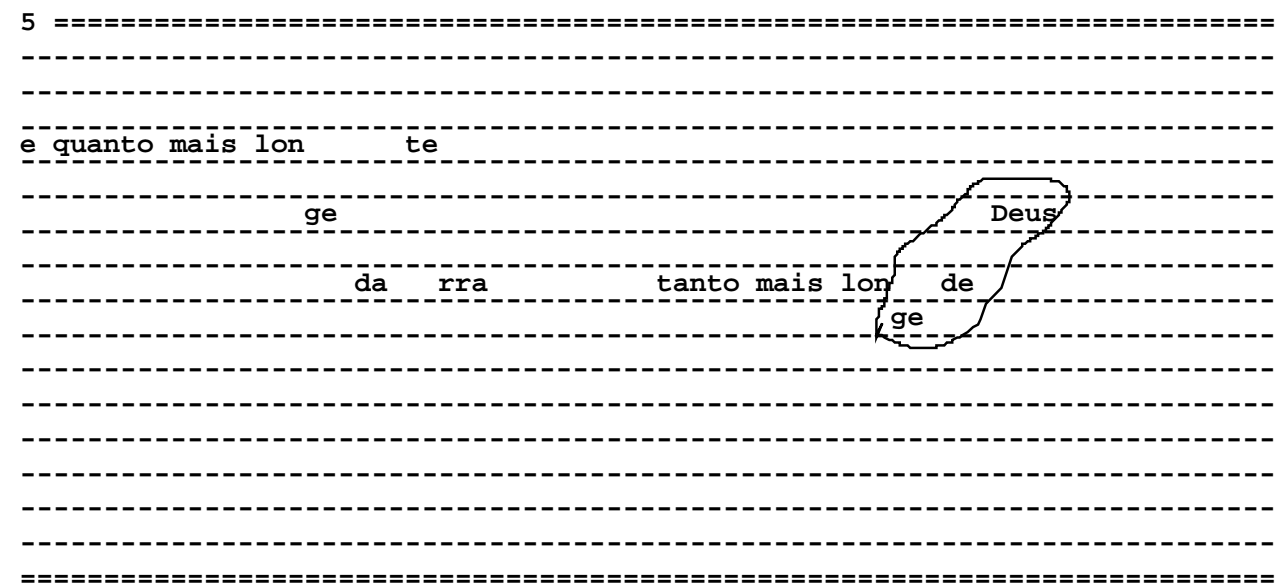

Por fim, a letra desta segunda parte só poderia confirmar os desígnios da melodia. Assim como esta se cristaliza em quatro temas, agrupados dois a dois no quarto e no quinto segmentos, a letra engendra a imagem do componês-lavrador do espaço sideral, qualificando-a, igualmente, com quatro motivos de conteúdo: "louco dos astros", "solto nos céus", "longe da terra" e "longe de Deus".

A esse processo de engendramento de imagens chamamos iconização, num sentido talvez mais próximo da semiótica européia que da americana. ${ }^{7}$ Temos iconização toda vez que aparecem diversos traços par configurar a mesma imagem, o mesmo objeto, o mesmo personagem ou até o mesmo sentimento. De qualquer forma, a característica marcante desse processo é a enumeração lingüística desses traços que faz ressoar as reiterações dos temas melódicos. Tudo ocorre como se a canção engendrasse um novo signo, em que o plano da expressão se define pela recorrência dos temas melódicos e o plano do conteúdo pela enumeração dos traços que compõem um ícone integral. Se a melodia assim concebida mexe diretamente com o nosso corpo pelos canais auditivo e tátil, a letra atinge nossa mente por esses

${ }^{7}$ Cf. A. J. Greimas et J. Courtés - Dicionário de semiótica, op. cit., p. 223. 
mesmos ou por outros canais sensitivos. Nesta canção por exemplo, as movimentações descritas na dimensão espacial evidenciam um apelo visual: "O lavrador louco dos astros / 0 camponês solto nos céus".

Assim, a dinamização do andamento melódico mais a equivalência de suas unidades rítmicas para excitar o processo reiterativo passam a ser o tema musical do camponês-lavrador impregnando-se de suas características. Este é o resultado geral da tematização que ocupa, nesta composição, o primeiro posto na hierarquia das estratégias persuasivas. De qualquer modo, é pela presença concomitante e coerente dos outros dois processos (passionalização e figurativização) preenchendo outras esferas do seu sentido, que A marra 0 teu arado a uma estrela integra-se na economia geral de sua linguagem e renova, a cada execução, o encanto e a eficácia da canção popular.

\section{Referências Bibliográficas}

GREIMAS, A. J. \& COURTÉS, J. [s.d] Dicionário de semiótica. São Paulo Cultrix. TATIT, L. [1996] 0 cancionista: composição de canções no Brasil. São Paulo, Edusp. TOMAS, N. [1966] Manual de entonacion española. Mexico, Malaga.

TARASTI, E. "Le rôle du temps dans le discours musical", in: ARRIVÉ, M \& COQUET, J-C (eds.). [1987] Sémiotique en jeu: à partir et autour de l'oeuvre de A. J. Greimas, Paris/ Amsterdam/ Philadelphia, Hadés-Benjamins. 